\title{
Does state malpractice environment affect outcomes following spinal fusions? A robust statistical and machine learning analysis of 549,775 discharges following spinal fusion surgery in the United States
}

\author{
Andrew K. Chan, MD, ${ }^{1}$ Michele Santacatterina, PhD, ${ }^{2}$ Brenton Pennicooke, MD, ${ }^{1}$ \\ Shane Shahrestani, MS, ${ }^{3}$ Alexander M. Ballatori, BA, ${ }^{3}$ Katie O. Orrico, JD, ${ }^{4}$ \\ John F. Burke, MD, PhD, ${ }^{1}$ Geoffrey T. Manley, MD, PhD, ${ }^{1}$ Phiroz E. Tarapore, MD, ${ }^{1}$ \\ Michael C. Huang, MD, ${ }^{1}$ Sanjay S. Dhall, MD, ${ }^{1}$ Dean Chou, MD, ${ }^{1}$ Praveen V. Mummaneni, MD, ${ }^{1}$ and \\ Anthony M. DiGiorgio, DO, MHA ${ }^{1}$
}

\begin{abstract}
${ }^{1}$ Department of Neurological Surgery, University of California, San Francisco, California; ${ }^{2}$ Cornell TRIPODS Center for Data Science for Improved Decision-Making and Cornell Tech, Cornell University, New York, New York; ${ }^{3 K e c k}$ School of Medicine, University of Southern California, Los Angeles, California; and ${ }^{4}$ American Association of Neurological Surgeons/Congress of Neurological Surgeons Washington Office, Washington, DC
\end{abstract}

\begin{abstract}
OBJECTIVE Spine surgery is especially susceptible to malpractice claims. Critics of the US medical liability system argue that it drives up costs, whereas proponents argue it deters negligence. Here, the authors study the relationship between malpractice claim density and outcomes.
\end{abstract}

METHODS The following methods were used: 1) the National Practitioner Data Bank was used to determine the number of malpractice claims per 100 physicians, by state, between 2005 and 2010; 2) the Nationwide Inpatient Sample was queried for spinal fusion patients; and 3) the Area Resource File was queried to determine the density of physicians, by state. States were categorized into 4 quartiles regarding the frequency of malpractice claims per 100 physicians. To evaluate the association between malpractice claims and death, discharge disposition, length of stay (LOS), and total costs, an inverse-probability-weighted regression-adjustment estimator was used. The authors controlled for patient and hospital characteristics. Covariates were used to train machine learning models to predict death, discharge disposition not to home, LOS, and total costs.

RESULTS Overall, 549,775 discharges following spinal fusions were identified, with 495,640 yielding state-level information about medical malpractice claim frequency per 100 physicians. Of these, 124,425 (25.1\%), 132,613 (26.8\%), 130,929 $(26.4 \%)$, and 107,673 (21.7\%) were from the lowest, second-lowest, second-highest, and highest quartile states, respectively, for malpractice claims per 100 physicians. Compared to the states with the fewest claims (lowest quartile), surgeries in states with the most claims (highest quartile) showed a statistically significantly higher odds of a nonhome discharge (OR $1.169,95 \% \mathrm{Cl} 1.139-1.200$ ), longer LOS (mean difference $0.304,95 \% \mathrm{Cl} 0.256-0.352$ ), and higher total charges (mean difference [log scale] $0.288,95 \% \mathrm{Cl} 0.281-0.295)$ with no significant associations for mortality. For the machine learning models-which included medical malpractice claim density as a covariate- the areas under the curve for death and discharge disposition were 0.94 and 0.87 , and the $R^{2}$ values for LOS and total charge were 0.55 and 0.60 , respectively.

CONCLUSIONS Spinal fusion procedures from states with a higher frequency of malpractice claims were associated with an increased odds of nonhome discharge, longer LOS, and higher total charges. This suggests that medicolegal climate may potentially alter practice patterns for a given spine surgeon and may have important implications for medical liability reform. Machine learning models that included medical malpractice claim density as a feature were satisfactory in prediction and may be helpful for patients, surgeons, hospitals, and payers.

https://thejns.org/doi/abs/10.3171/2020.8.FOCUS20610

KEYWORDS liability; malpractice; tort; spine; surgery; claims

\footnotetext{
ABBREVIATIONS DRG = diagnosis-related group; GBC = gradient boosting classifier; GBR = gradient boosting regressor; ICD-9-CM = International Classification of Diseases, Ninth Revision, Clinical Modification; LOS = length of stay; MICE = multivariate imputation by chained equations; NIS = Nationwide Inpatient Sample; NPDB = National Practitioner Data Bank.
} 
$\mathrm{M}$ EDICAL malpractice adds significant costs to the US healthcare system. As of 2009, approximately $\$ 55.6$ billion $(2.4 \%$ of healthcare spending) was spent on malpractice annually. ${ }^{1}$ These costs are due to both direct costs (e.g., settlements, awards, and malpractice insurance premiums) and defensive medicine.

The medical liability (tort) system is intended to serve three functions: compensate patients injured by negligence, promote corrective justice, and deter negligence. However, critics of the US medical liability system argue that it may not lead to better healthcare quality and in addition may increase the total cost of healthcare delivery. Others suggest that the medical liability system lowers physician satisfaction, impairs the patient-physician relationship, and reduces access to care. . $^{2,3}$

There are various methods of tort reform across the different states in the US. These include caps on noneconomic damages, medical review panels, and attorney fee limits. This has led to variable malpractice climates between the different states. By comparing health outcomes across these states, it is possible to investigate the impact of malpractice climate on patient outcomes. For instance, if the tort system deters negligence, patients may have better outcomes in malpractice climates that encourage more litigation. On the other hand, if the tort system obstructs healthcare delivery, there may be better outcomes with lower liability and increased access to care ${ }^{3-5}$ because physicians may be more willing to take on higher-risk procedures. ${ }^{6}$ Indeed, such investigations have been undertaken in fields such as general surgery, obstetrics and gynecology, and colorectal surgery ${ }^{7-9}$ and have failed to show any clear association between medical malpractice climate and patient outcomes. In neurosurgical practices-surgeons who face among the highest frequency of malpractice claims among medical specialties ${ }^{10,11}$ - a highly litigious medical liability climate was found to have no effect on outcomes after cranial surgery as well. ${ }^{12}$

Within neurosurgery, spine surgery faces the highest risk of litigation. ${ }^{13-15}$ Despite the potential relevance to this field, the association between medical malpractice climate and spine surgery outcomes remains incompletely defined. ${ }^{16}$ To this end, we examined the effect of medical liability climate on outcomes after spine surgery. We used a doubly robust, inverse-probability-weighted regressionadjustment estimator to assess 1) the impact of medical malpractice claim density on outcomes following more than half a million spinal fusion surgeries in the US and 2) the interaction between spinal fusion outcomes, claim density, and patient income. Additionally, we constructed machine learning models_-including medical malpractice claim density as a covariate-in order to predict outcomes following spinal fusion surgery.

\section{Methods}

\section{Data Source}

Patient Sample-Nationwide Inpatient Sample

Using International Classification of Diseases, Ninth Revision, Clinical Modification (ICD-9-CM) coding (Table 1), we identified discharges from nonfederal hospitals in the US of patients who underwent spinal fusion surgery
TABLE 1. ICD-9 procedure codes used to identify patients undergoing spinal fusion surgery in the NIS between 2005 and 2010

\begin{tabular}{|c|c|}
\hline $\begin{array}{c}\text { ICD-9 } \\
\text { Procedure } \\
\text { Code }\end{array}$ & Description \\
\hline 81.00 & Spinal fusion, not otherwise specified \\
\hline 81.01 & Atlas-axis spinal fusion \\
\hline 81.02 & $\begin{array}{l}\text { Other cervical fusion of the anterior column, anterior } \\
\text { technique }\end{array}$ \\
\hline 81.03 & $\begin{array}{l}\text { Other cervical fusion of the posterior column, posterior } \\
\text { technique }\end{array}$ \\
\hline 81.04 & $\begin{array}{l}\text { Dorsal and dorsolumbar fusion of the anterior column, } \\
\text { anterior technique }\end{array}$ \\
\hline 81.05 & $\begin{array}{l}\text { Dorsal and dorsolumbar fusion of the posterior column, } \\
\text { posterior technique }\end{array}$ \\
\hline 81.06 & $\begin{array}{l}\text { Lumbar and lumbosacral fusion of the anterior column, } \\
\text { anterior technique }\end{array}$ \\
\hline 81.07 & $\begin{array}{l}\text { Lumbar and lumbosacral fusion of the posterior column, } \\
\text { posterior technique }\end{array}$ \\
\hline 81.08 & $\begin{array}{l}\text { Lumbar and lumbosacral fusion of the anterior column, } \\
\text { posterior technique }\end{array}$ \\
\hline 81.62 & Fusion or refusion of $2-3$ vertebrae \\
\hline 81.63 & Fusion or refusion of $4-8$ vertebrae \\
\hline 81.64 & Fusion or refusion of 9 or more vertebrae \\
\hline
\end{tabular}

between 2005 and 2010 and whose cases were recorded in the Healthcare Cost and Utilization Project (HCUP) Nationwide Inpatient Sample (NIS). The NIS is one of the largest publicly available all-payer inpatient databases in the US and contains data on more than 7 million hospital discharges each year.

\section{Size of Malpractice Claims-National Practitioner Data Bank}

The National Practitioner Data Bank (NPDB) is a deidentified database created by Congress with information regarding medical malpractice claims and sizes. The NPDB was queried for all malpractice claims between 2005 and 2010. The number of claims per 100 physicians was summed by state. States were ranked by the number of claims per 100 physicians and separated into 4 quartiles, namely: lowest (minimum number of claims to 1st quartile of the distribution of claims per 100 physicians); second lowest (1st quartile to 2 nd quartile of the distribution of claims per 100 physicians); second highest (2nd quartile to 3 rd quartile of the distribution of claims per 100 physicians); and highest (3rd quartile to maximum number of claims per 100 physicians). Minimum, 1st quartile, 2nd quartile, 3rd quartile, and maximum claims were equal to $0.00005,0.0013,0.0018,0.0019$, and 0.007 claims per 100 physicians, respectively. Discharges abstracted from the NIS were assigned into these four groups accordingly.

\section{Physician Density—Area Resource File}

The Area Resource File is an annual database containing information regarding the number of physicians per county per state. These frequencies were adjusted by state 
population sizes to calculate the density of physicians per state, which was linked to the NIS data set for analysis.

\section{Discharge Characteristics}

We considered the following covariates: race (White, Black, Hispanic, Asian or Pacific Islander, Native American, or other); age; sex (female or male); median household income for patient's zip code (quartiles 1-4 and other as defined by the NIS ${ }^{17}$ ); expected primary payer (other, Medicare, Medicaid, private insurance, self-pay, or no charge); calendar year (2005-2010); number of days from admission to procedure; admission type; discharge quarter (January-March, April-June, July-September, or October-December); location/teaching status of hospital (rural, urban nonteaching, or urban teaching); physician density; hospital bed size (small, medium, or large); region of hospital (Northeast, Midwest, South, or West); congestive heart failure; Charlson Comorbidity Index ${ }^{18}$ presence of in-hospital ICD-9 identifiable complications; and metastatic carcinoma. In addition, we considered the following covariates (not shown in Table 2): admission month, hospital state postal code; hospital FIPS (Federal Information Processing Standards) state/county code; major diagnostic category in effect on discharge date; ICD-9-CM diagnosis; Clinical Classifications Software for ICD-9-CM diagnosis classification; ICD-9-CM procedure; Clinical Classifications Software for ICD-9-CM procedures; diagnosisrelated group (DRG) or Medicare Severity-DRG version used on discharge date; and DRG in use on discharge date.

\section{Outcome Measures}

We considered the following outcome measures: death (binary-dead or alive); discharge not to home (binarynot to home vs to home); length of stay (LOS; continuous); and total charges (continuous, log scale).

\section{Statistical Analysis}

Descriptive statistics, percentages, mean and SD were computed to describe characteristics of the study population. Chi-square tests for binary and categorical variables and ANOVA for continuous variables were used to evaluate the marginal relationship between covariates and categories of malpractice claims.

Multivariate imputation by chained equations (MICE) ${ }^{19}$ was used to impute the missing values. The following univariate imputation techniques were used: predictive mean matching for continuous covariates; logistic regression for binary covariates; multinomial logit model for covariates with more than 2 factors; and ordered logit model for features with ordered covariates. All covariates presented before and the categories of malpractice claims were included in the analysis with MICE.

To evaluate the relationship between categories of malpractice claims and outcomes, an inverse-probability-weighted regression-adjustment estimator ${ }^{20}$ was used. This estimator is known as doubly robust ${ }^{21}$ in the sense that unbiased results can be obtained whenever either the outcome model or the inverse-probability model is correctly specified, thus leading to more robust results. Inverse-probability weights were obtained by using a multi- nomial logistic regression model, which modeled the relationship between categories of malpractice claims and covariates. To avoid extreme values, weights were truncated at the 95th percentile. ${ }^{22}$ To model the relationship between the four outcomes and the quartiles of malpractice claims, a multivariate logistic regression for death and discharge not to home and a multivariate linear regression for LOS and $(\log )$ total charges weighted by the inverse-probability weights were used. We used the same set of covariates for both the inverse-probability weights model and the outcome models. A sandwich estimator was used to construct 95\% Wald CIs. ${ }^{23}$ These analyses were repeated with stratification based on quartile of median household income for a patient's zip code. Statistical significance was defined as $\alpha<0.05$. All statistical analyses were conducted in RStudio and R (versions 1.2.5001 and 3.6.3, respectively).

To predict the risk of death and discharge not to home, a gradient boosting classifier (GBC) was used. To predict the LOS in days and the $(\log )$ total charges, a gradient boosting regressor (GBR) was used. We used fivefold cross-validation to estimate prediction accuracy, mean square error, and $\mathrm{R}^{2}$, and we chose the best hyperparameters. We followed standard machine learning practice and randomly split the whole data set into $80 \%$ training and $20 \%$ testing data. Because death and discharge not to home outcomes were highly unbalanced (death occurred in $0.4 \%$ of the entire population under study, whereas discharge not to home occurred in $24 \%$ ), we upsampled the minority class of these two outcomes in the training data set. Prediction algorithms were conducted using Python version 3.6.9.

\section{Results}

We identified 549,775 patients who underwent spinal fusion between 2005 and 2010. Of these, 495,640 had available data about frequency of malpractice claims per 100 physicians. Cohort characteristics for these 495,640 patients, stratified by malpractice claim density, can be found in Table 2. States in the highest quartile for the number of claims included Texas, Nebraska, Kansas, Oklahoma, Montana, Georgia, Louisiana, Mississippi, Iowa, Illinois, and Pennsylvania. States in the lowest quartile for the number of claims included Hawaii, Rhode Island, Connecticut, Massachusetts, New Hampshire, Vermont, Maine, Maryland, New Jersey, Alaska, and Arizona.

Table 3 reports the inverse-probability-weighted regression-adjustment estimator analyses modeling the relationships between death, discharge disposition, LOS, and total hospital charges and frequency of malpractice claims per 100 physicians. The models revealed significant associations between malpractice claim frequency per 100 physicians and discharge disposition, LOS, and total charges. Compared to spinal fusions performed in the lowest malpractice claim density states, those spinal fusions performed in states with the highest malpractice claim density had higher odds of discharge disposition not to home. Spinal fusions performed in states with higher malpractice claim density were associated with longer lengths of hospitalization. For total hospital charges, spinal fusions performed in states with higher malpractice claim density were associated with higher charges. There 
TABLE 2. Cohort characteristics, stratified by quartile of number of medical malpractice claims per 100 physicians by state

\begin{tabular}{|c|c|c|c|c|c|c|}
\hline Characteristic & Total, $N=495,640$ & $\begin{array}{l}\text { Lowest Quartile, } \\
\qquad n=124,425\end{array}$ & $\begin{array}{c}\text { 2nd-Lowest } \\
\text { Quartile, } \\
n=132,613\end{array}$ & $\begin{array}{c}\text { 2nd-Highest } \\
\text { Quartile, } \\
n=130,929\end{array}$ & $\begin{array}{c}\text { Highest } \\
\text { Quartile, } \\
n=107,673\end{array}$ & p Value \\
\hline Age, yrs $( \pm S D)$ & $53( \pm 17)$ & $53( \pm 16)$ & $51( \pm 20)$ & $54( \pm 16)$ & $52( \pm 17)$ & $<0.001$ \\
\hline Women & $270,290(55)$ & $66,537(54)$ & $73,710(56)$ & $71,229(54)$ & $58,814(55)$ & $<0.001$ \\
\hline $\mathrm{CCl}( \pm \mathrm{SD})$ & $4( \pm 2)$ & $4( \pm 2)$ & $4( \pm 2)$ & $4( \pm 2)$ & $4( \pm 2)$ & $<0.001$ \\
\hline Congestive heart failure & $3,711(1)$ & $990(0.8)$ & $1,123(0.8)$ & $909(0.7)$ & $689(0.6)$ & $<0.001$ \\
\hline Metastatic carcinoma & $25,109(5)$ & $5,745(5)$ & $10,189(8)$ & $5,882(4)$ & $3,293(3)$ & $<0.001$ \\
\hline In-hospital, periop complication* & $70,334(14)$ & $18,957(15)$ & $18,441(14)$ & $18,927(14)$ & $14,009(13)$ & $<0.001$ \\
\hline Race & & & & & & $<0.001$ \\
\hline White & $344,754(81)$ & $93,207(79)$ & $94,891(81)$ & $85,270(85)$ & $71,386(79)$ & \\
\hline Black & $35,434(8)$ & $8,877(8)$ & $10,899(9)$ & $7,691(8)$ & $7,967(9)$ & \\
\hline Hispanic & $26,546(6)$ & $10,382(9)$ & $5,150(4)$ & $3,993(4)$ & $7,021(8)$ & \\
\hline Asian or Pacific Islander & $5,226(1)$ & $2,575(2)$ & $1,261(1)$ & $847(0.8)$ & $543(0.6)$ & \\
\hline Native American & $2,064(0)$ & $417(0.4)$ & $343(0.3)$ & $395(0.4)$ & $909(1)$ & \\
\hline Other & $11,741(3)$ & $2,463(2)$ & $3,964(3)$ & $2,666(3)$ & $2,648(3)$ & \\
\hline $\begin{array}{l}\text { Median household income for patient's } \\
\text { zip code }\end{array}$ & & & & & & $<0.001$ \\
\hline Quartile 1 & $95,751(19)$ & $15,360(12)$ & $24,144(18)$ & $25,037(19)$ & $31,210(29)$ & \\
\hline Quartile 2 & $109,364(22)$ & $19,734(16)$ & $28,266(21)$ & $36,653(28)$ & $24,711(23)$ & \\
\hline Quartile 3 & $108,862(22)$ & $28,111(23)$ & $29,256(22)$ & $30,546(23)$ & $20,949(19)$ & \\
\hline Quartile 4 & $102,849(21)$ & $37,646(30)$ & $31,530(24)$ & $19,524(15)$ & $14,149(13)$ & \\
\hline Other & $78,814(16)$ & $23,574(19)$ & $19,417(15)$ & $19,169(15)$ & $16,654(15)$ & \\
\hline Expected primary payer & & & & & & $<0.001$ \\
\hline Other & $53,321(11)$ & $16,910(14)$ & $12,881(10)$ & $11,239(9)$ & $12,291(11)$ & \\
\hline Medicare & $148,466(30)$ & $35,916(29)$ & $39,300(30)$ & $42,372(32)$ & $30,878(29)$ & \\
\hline Medicaid & $37,642(8)$ & $9,044(7)$ & $12,237(9)$ & $9,204(7)$ & $7,157(7)$ & \\
\hline Private insurance & $245,302(49)$ & $60,776(49)$ & $64,953(49)$ & $65,256(50)$ & $54,317(50)$ & \\
\hline Self-pay & $10,021(2)$ & $1,641(1)$ & $3,176(2)$ & $2,481(2)$ & $2,723(3)$ & \\
\hline No charge & $888(0)$ & $138(0.1)$ & $66(0.05)$ & $377(0.3)$ & $307(0.3)$ & \\
\hline Calendar year & & & & & & $<0.001$ \\
\hline 2005 & $68,281(14)$ & $20,523(16)$ & $16,351(12)$ & $16,883(13)$ & $14,524(13)$ & \\
\hline 2006 & $74,048(15)$ & $20,867(17)$ & $20,597(16)$ & $17,621(13)$ & $14,963(14)$ & \\
\hline 2007 & $87,129(18)$ & $21,024(17)$ & $29,141(22)$ & $20,250(15)$ & $16,714(16)$ & \\
\hline 2008 & $82,062(17)$ & $19,916(16)$ & $21,558(16)$ & $23,895(18)$ & $16,693(16)$ & \\
\hline 2009 & $92,385(19)$ & $20,168(16)$ & $27,638(21)$ & $23,369(18)$ & $21,210(20)$ & \\
\hline 2010 & $91,735(19)$ & $21,927(18)$ & $17,328(13)$ & $28,911(22)$ & $23,569(22)$ & \\
\hline $\begin{array}{l}\text { No. of days from admission to procedure } \\
( \pm \text { SD) }\end{array}$ & $0.4( \pm 2)$ & $0.5( \pm 2)$ & $0.6( \pm 3)$ & $0.4( \pm 2)$ & $0.4( \pm 2)$ & $<0.001$ \\
\hline Admission type & & & & & & $<0.001$ \\
\hline Emergency & $44,292(10)$ & $8,364(11)$ & $16,896(13)$ & $10,391(8)$ & $8,641(8)$ & \\
\hline Urgent & $38,022(8)$ & $4,886(6)$ & $8,476(6)$ & $11,710(9)$ & $12,950(12)$ & \\
\hline Elective & $358,106(80)$ & $65,220(82)$ & $101,677(77)$ & $107,410(82)$ & $83,799(78)$ & \\
\hline Trauma & $3,416(1)$ & $741(0.9)$ & $828(0.6)$ & $1,190(0.9)$ & $657(0.6)$ & \\
\hline Other & $6,226(1)$ & $301(0.2)$ & $4,642(4)$ & $173(0.1)$ & $1,110(1)$ & \\
\hline Discharge quarter & & & & & & $<0.001$ \\
\hline 1st quarter, Jan-Mar & $122,108(25)$ & $31,031(25)$ & $33,044(25)$ & $32,198(25)$ & $25,835(24)$ & \\
\hline 2nd quarter, Apr-Jun & $125,135(25)$ & $31,354(25)$ & $33,407(25)$ & $32,810(25)$ & $27,564(26)$ & \\
\hline 3rd quarter, Jul-Sep & $121,959(25)$ & $30,599(25)$ & $32,533(25)$ & $32,398(25)$ & $26,429(25)$ & \\
\hline 4th quarter, Oct-Dec & $126,044(25)$ & $31,441(25)$ & $33,235(25)$ & $33,523(26)$ & $27,845(26)$ & \\
\hline
\end{tabular}


TABLE 2. Cohort characteristics, stratified by quartile of number of medical malpractice claims per 100 physicians by state

\begin{tabular}{|c|c|c|c|c|c|c|}
\hline Characteristic & Total, $N=495,640$ & $\begin{array}{l}\text { Lowest Quartile, } \\
\qquad n=124,425\end{array}$ & $\begin{array}{c}\text { 2nd-Lowest } \\
\text { Quartile, } \\
n=132,613\end{array}$ & $\begin{array}{c}\text { 2nd-Highest } \\
\text { Quartile, } \\
n=130,929\end{array}$ & $\begin{array}{c}\text { Highest } \\
\text { Quartile, } \\
n=107,673\end{array}$ & p Value \\
\hline Location/teaching status of hospital & & & & & & $<0.001$ \\
\hline Rural & $25,493(5)$ & $5,718(5)$ & $6,506(5)$ & $8,213(6)$ & $5,056(5)$ & \\
\hline Urban nonteaching & $231,120(47)$ & $59,032(48)$ & $61,381(46)$ & $58,092(44)$ & $52,615(50)$ & \\
\hline Urban teaching & $234,942(48)$ & $58,926(48)$ & $64,718(49)$ & $64,439(49)$ & $46,859(45)$ & \\
\hline Density, physicians $/ 100,000$ pop $( \pm$ SD) & $1658( \pm 2945)$ & $4434( \pm 4770)$ & $544( \pm 534)$ & $1145( \pm 858)$ & $446( \pm 385)$ & $<0.001$ \\
\hline Bed size of hospital & & & & & & $<0.001$ \\
\hline Small & $67,529(14)$ & $16,341(13)$ & $14,659(11)$ & $10,943(8)$ & $25,586(24)$ & \\
\hline Medium & $115,933(24)$ & $30,453(25)$ & $33,502(25)$ & $25,337(19)$ & $26,641(25)$ & \\
\hline Large & $308,093(63)$ & $76,882(62)$ & $84,444(64)$ & $94,464(72)$ & $52,303(50)$ & \\
\hline Region of hospital & & & & & & $<0.001$ \\
\hline Northeast & $80,645(16)$ & $34,820(28)$ & $33,384(25)$ & $12,441(10)$ & $0(0)$ & \\
\hline Midwest & $80,119(16)$ & $0(0)$ & $15,704(12)$ & $40,216(31)$ & $24,199(22)$ & \\
\hline South & $216,282(44)$ & $22,729(18)$ & $41,270(31)$ & $68,809(53)$ & $83,474(78)$ & \\
\hline West & $118,594(24)$ & $66,876(54)$ & $42,255(32)$ & $9,463(7)$ & $0(0)$ & \\
\hline
\end{tabular}

$\mathrm{CCl}=$ Charlson Comorbidity Index; pop = population.

Values are presented as number (\%) unless otherwise indicated.

${ }^{*}$ Complications were identified by the presence of the following ICD-9 diagnosis codes during a hospitalization: $342.00-342.92,349.0,349.1,349.2,349.31,349.39$, $349.89,349.9,415.11,415.19,415.40,415.41,415.42,599.0,900.00,900.01,900.02,900.03,900.1,900.81,900.82,900.89,900.9,901.0,902.0,902.10,902.11$, $902.19,902.40,902.41,902.42,902.49,902.50,902.51,902.52,902.53,902.54,902.55,902.56,902.59,902.87,902.89,902.9,996.2,996.40,996.41,996.42$, $996.43,996.44,996.45,996.46,996.47,996.49,996.60,996.63,996.64,996.66,996.67,996.69,996.70,996.75,996.77,996.78,996.79,997.00,997.01,997.02$, $997.09,997.1,997.2,997.31,997.32,997.39,997.49,997.5,997.72,997.79,997.91,997.99,998.00,998.01,998.02,998.09,998.11,998.12,998.13,998.2,998.30$, 998.31, 998.32, 998.4, 998.51, 998.59, 998.6, 998.7, 998.81, 998.83, 998.89, 998.9, 999.1, 999.2, 999.31, 999.32, 999.33, 999.34, 999.39, 999.41, 999.42, 999.49, 999.51, 999.52, 999.59, 996.60, 999.61, 999.62, 999.63. 999.69, 999.70, 999.71, 999.72, 999.73, 999.74, 999.75, 999.76, 999.77, 999.78, 999.79, 999.80, 999.81, $999.82,999.83,999.84,999.85,999.88,999.89,999.9$.

was no significant association between malpractice claim density and mortality $(\mathrm{p}>0.05)$.

Table 4 reports similar analyses, stratified by quartile of median household income for a patient's zip code. For those from the lowest-income zip codes, higher density of malpractice claims was associated with fewer deaths - not observed in patients from the highest-income zip codes. For discharge disposition, the association between medical malpractice claim density and outcome depended on income quartile. For those from the lowest income quartile, higher malpractice claim density was associated with discharge not to home. In contrast, for those from the highest income quartile, higher malpractice claim density was associated with discharge to home. When conducting stratified analyses, higher malpractice claim density was associated with decreased LOS (opposite in direction to the nonstratified analysis) and higher total charges (similar to the nonstratified analysis).

Table 5 shows the performance of the GBC and GBR in the test data set. Performance measures were all satisfactory except for the positive predictive value (which is the probability that, given that the algorithm predicted that a patient will die, the patient actually dies) of the machine learning algorithm for death. This is due to the fact that the class death was highly unbalanced. Careful considerations should be taken in using this algorithm to predict mortality. The most predicting feature for death was admission type, for discharge not to home it was age, for LOS it was the number of days from admission to procedure, and for total charges $(\log )$ it was the DRG in use on the discharge date.

\section{Discussion}

In a robust analysis of more than half a million discharges for spinal fusion surgery in the US, state malpractice claim density demonstrated significant associations with multiple patient outcomes despite adjustment for various patient and hospital covariates. Patients with spinal fusions from states with a higher medical malpractice claim density had a higher odds of nonhome discharge, longer lengths of hospitalization, and higher total hospital charges compared to those with spinal fusions performed in states with fewer medical malpractice claims per 100 physicians. There was no observed association with mortality. In a subgroup analysis, the association between malpractice claim density and discharge disposition differed in directionality, however, depending on patient income. Those in the lowest income quartile were more often discharged not to home in higher claims environments, whereas those in the highest income quartile were more often discharged to home in higher claims environments. Machine learning models using medical malpractice claim density as a covariate were satisfactory in predicting outcomes following spinal fusion surgery.

A primary goal of the medical liability system is to de- 
TABLE 3. Inverse-probability-weighted regression-adjustment estimator modeling the relationships between outcomes and frequency of malpractice claims per 100 physicians

\begin{tabular}{|c|c|c|c|c|}
\hline \multirow{2}{*}{$\begin{array}{c}\text { Frequency of Malpractice } \\
\text { Claims/100 Physicians }\end{array}$} & \multicolumn{2}{|c|}{$\mathrm{OR}(95 \% \mathrm{Cl})$} & \multicolumn{2}{|c|}{ Linear Increase $(95 \% \mathrm{Cl})$} \\
\hline & Death & Discharge Not to Home & LOS & Total Charges (log) \\
\hline Lowest quartile & Ref & Ref & Ref & Ref \\
\hline 2nd-lowest quartile & $1.143(0.989-1.322)$ & $1.096(1.068-1.124)^{*}$ & $0.157(0.111-0.203)^{*}$ & $0.016(0.009-0.022)^{*}$ \\
\hline 2nd-highest quartile & $0.961(0.819-1.127)$ & $0.948(0.925-0.971)^{*}$ & $0.125(0.080-0.170)^{*}$ & $0.247(0.241-0.253)^{*}$ \\
\hline Highest quartile & $1.041(0.880-1.232)$ & $1.169(1.139-1.200)^{*}$ & $0.304(0.256-0.352)^{*}$ & $0.288(0.281-0.295)^{*}$ \\
\hline
\end{tabular}

${ }^{*}$ Denotes significant relationship between frequency of malpractice claims per 100 physicians and specified outcome, compared to the reference, at $p<0.05$.

ter negligence and reduce harm to patients. From the perspective of the patient, this may take the form of reducing complications and eliminating mortality following surgery. In our study, we found no overall association between medical malpractice climate and mortality rate following spinal fusion surgery, consistent with a prior report by Missios and Bekelis ${ }^{16}$ assessing the association between claim density and mortality following 709,951 patients undergoing spine surgery whose cases were recorded in the NIS. In their study, the authors reported that states with a higher frequency of malpractice claims also showed higher hospital charges. Notably, the authors used multivariable logistic regression and excluded missing variables from the analysis entirely by using listwise deletion, introducing bias. Missing data-a noteworthy problem in large, administrative data sets-can result in an under- or overestimation of treatment effects, ${ }^{24-26}$ depending on the mechanism of missingness, and may limit statistical power. ${ }^{27}$ To address this potential issue, we used MICE and a doubly robust inverse-probability-weighted regression-adjustment estimator in order to rigorously assess the association between malpractice claim density and mortality. In doing so, we provide evidence supporting Missios and Bekelis's finding that medical malpractice claim density does not significantly associate with mortality. This is consistent with investigations outside of spine surgery, ${ }^{9,28}$ including cranial neurosurgery. ${ }^{12}$ A review by Minami et al. in 2014 did not find that the threat of litigation improved physician adherence to quality indicators or led to better outcomes. ${ }^{28}$ Similarly, a review of 20 studies across nonobstetrical care and 16 studies in obstetrics by Mello et al. found little evidence to suggest that liability risk leads to better outcomes. ${ }^{9}$ In fact,

TABLE 4. Inverse-probability-weighted regression-adjustment estimator modeling the relationships between outcomes and frequency of malpractice claims per 100 physicians, stratified by income quartile

\begin{tabular}{|c|c|c|c|c|c|}
\hline \multirow{3}{*}{$\begin{array}{l}\text { Income } \\
\text { Quartile }\end{array}$} & \multirow{3}{*}{$\begin{array}{c}\text { Frequency of } \\
\text { Malpractice } \\
\text { Claims/100 Physicians }\end{array}$} & \multicolumn{2}{|c|}{ OR $(95 \% \mathrm{Cl})$} & \multicolumn{2}{|c|}{ Linear Increase $(95 \% \mathrm{Cl})$} \\
\hline & & & Discharge Not to & & \\
\hline & & Death & Home & LOS & Total Charges (log) \\
\hline \multirow{4}{*}{$\begin{array}{l}\text { Lowest income } \\
\text { quartile }\end{array}$} & Lowest quartile & Ref & Ref & Ref & Ref \\
\hline & 2nd-lowest quartile & $1.031(0.785$ to 1.356$)$ & $1.169(1.111 \text { to } 1.230)^{*}$ & $-0.308(-0.494 \text { to }-0.121)^{*}$ & $-0.308(-0.333 \text { to }-0.284)^{*}$ \\
\hline & 2nd-highest quartile & $0.524(0.384 \text { to } 0.714)^{*}$ & 1.037 (0.987 to 1.089$)$ & $-0.237(-0.411 \text { to }-0.063)^{*}$ & $0.17(0.149 \text { to } 0.191)^{*}$ \\
\hline & Highest quartile & $0.611(0.458 \text { to } 0.817)^{*}$ & 1.048 (0.999 to 1.099) & $-0.358(-0.529 \text { to }-0.187)^{*}$ & $0.050(0.030 \text { to } 0.071)^{*}$ \\
\hline \multirow{4}{*}{$\begin{array}{l}\text { 2nd-lowest in- } \\
\text { come quartile }\end{array}$} & Lowest quartile & Ref & Ref & Ref & Ref \\
\hline & 2nd-lowest quartile & $1.440(1.089 \text { to } 1.905)^{*}$ & $1.107(1.054 \text { to } 1.164)^{*}$ & $0.021(-0.160$ to 0.201$)$ & $-0.128(-0.149 \text { to }-0.106)^{*}$ \\
\hline & 2nd-highest quartile & $0.716(0.541 \text { to } 0.948)^{*}$ & $0.985(0.943$ to 1.029$)$ & $-0.293(-0.423 \text { to }-0.162)^{*}$ & $0.098(0.080 \text { to } 0.117)^{*}$ \\
\hline & Highest quartile & 0.984 (0.728 to 1.329$)$ & $0.926(0.883 \text { to } 0.971)^{*}$ & $0.206(0.064 \text { to } 0.347)^{\star}$ & $0.243(0.224 \text { to } 0.262)^{*}$ \\
\hline \multirow{4}{*}{$\begin{array}{l}\text { 2nd-highest in- } \\
\text { come quartile }\end{array}$} & Lowest quartile & Ref & Ref & Ref & Ref \\
\hline & 2nd-lowest quartile & 0.907 (0.687 to 1.196$)$ & 0.991 (0.946 to 1.038$)$ & $-0.137(-0.294$ to 0.019$)$ & $0.003(-0.018$ to 0.025$)$ \\
\hline & 2nd-highest quartile & $0.506(0.387 \text { to } 0.663)^{*}$ & $0.794(0.762 \text { to } 0.827)^{*}$ & $0.061(-0.075$ to 0.197$)$ & $0.359(0.342 \text { to } 0.377)^{*}$ \\
\hline & Highest quartile & $0.738(0.555$ to 0.980$)$ & $0.993(0.947$ to 1.040$)$ & $-0.012(-0.165$ to 0.141$)$ & 0.184 (0.166 to 0.203$)$ \\
\hline \multirow{4}{*}{$\begin{array}{l}\text { Highest in- } \\
\text { come quartile }\end{array}$} & Lowest quartile & Ref & Ref & Ref & Ref \\
\hline & 2nd-lowest quartile & $1.237(0.930$ to 1.646$)$ & $0.950(0.906 \text { to } 0.996)^{*}$ & $-0.251(-0.415 \text { to }-0.088)^{*}$ & $-0.018(-0.042$ to 0.005$)$ \\
\hline & 2nd-highest quartile & 0.745 (0.535 to 1.037$)$ & $0.83(0.791 \text { to } 0.871)^{*}$ & $-0.082(-0.235$ to 0.072$)$ & $0.422(0.399 \text { to } 0.444)^{*}$ \\
\hline & Highest quartile & $0.819(0.572$ to 1.173$)$ & $0.866(0.822 \text { to } 0.913)^{*}$ & $-0.267(-0.441 \text { to }-0.094)^{*}$ & $0.256(0.235 \text { to } 0.277)^{*}$ \\
\hline
\end{tabular}

* Denotes significant relationship between frequency of malpractice claims per 100 physicians and specified outcome, compared to the reference, at $p<0.05$. 
TABLE 5. Performance of the GBC and GBR in the test data set

\begin{tabular}{|c|c|c|c|c|c|}
\hline \multicolumn{3}{|c|}{ GBC } & \multicolumn{3}{|c|}{ GBR } \\
\hline $\begin{array}{l}\text { Performance } \\
\text { Measure* }^{*}\end{array}$ & Death & $\begin{array}{l}\text { Discharge } \\
\text { Not to Home }\end{array}$ & $\begin{array}{c}\text { Performance } \\
\text { Measure* }^{*}\end{array}$ & LOS & $\begin{array}{c}\text { Total } \\
\text { Charges } \\
(\log )\end{array}$ \\
\hline Accuracy & 0.86 & 0.79 & $\mathrm{R}^{2}$ & 0.55 & 0.60 \\
\hline $\begin{array}{l}\text { PPV } \\
\text { (precision) }\end{array}$ & 0.03 & 0.59 & & & \\
\hline NPV & 0.99 & 0.91 & & & \\
\hline $\begin{array}{l}\text { Sensitivity } \\
\text { (recall) }\end{array}$ & 0.89 & 0.77 & & & \\
\hline Specificity & 0.86 & 0.79 & & & \\
\hline AUC & 0.94 & 0.87 & & & \\
\hline
\end{tabular}

AUC = area under the curve; NPV = negative predictive value $; P P V=$ positive predictive value.

* The higher the better. GBC for death resulted in the following best hyperparameters: $n \_$estimators $=1000$, learning_rate $=0.01$, max_features $=10$, max_depth $=10$; $G B C$ for discharge not to home: $n \_$estimators $=1000$, learning_rate $=0.1$, max_features $=3$, max_depth $=10$; GBR for LOS: $n \_$estimators $=1000$, learning_rate $=0.1$, max_features $=10$, max_depth $=10$; and $G B R$ for total charges: $n \_$estimators $=1000$, learning_rate $=0.1$, max_features $=10$, max_depth $=10$

we detected a significant association between high medical malpractice claim density and higher odds of nonhome discharge, which has not been described in spine surgery previously. This is supported by a previous investigation following 189,103 cranial neurosurgical procedures, in which the authors found a similar association between nonhome discharge and higher claim density. The association is probably multifactorial and may be a result of risk-adverse discharge practices favoring discharge to acute rehabilitation or a skilled nursing facility - as opposed to home or home with home healthcare-for borderline patients.

Similarly to Missios and Bekelis, we found that states with a higher frequency of malpractice claims also showed longer hospitalizations and higher total charges following spinal fusion surgery (the latter despite adjustment for LOS). ${ }^{16}$ Higher malpractice awards and premiums have been linked to higher medical spending ${ }^{29}$ which is likely to be driven by defensive medicine. ${ }^{3,12,30,31}$ Indeed, the costs of defensive medicine among orthopedic surgeons have been estimated at more than US\$2 billion per year. ${ }^{32} \mathrm{~A}$ large part of this is probably driven by "assurance behavior," such as performing excess tests, diagnostic procedures, consultations, and imaging. To this point, in a study by Studdert et al. in which the authors surveyed 824 emergency medicine, general surgery, orthopedic surgery, neurosurgery, obstetrics/gynecology, and radiology physicians, $43 \%$ of physicians in states with high malpractice claims reported ordering imaging purely for defensive medicine. ${ }^{31}$ Importantly, this finding - total charges increasing with higher malpractice claim density-remained when stratifying patients by income level and despite adjustment for covariates such as race, insurance, comorbidity, the presence of in-hospital complications, and LOS. In the modern era of value-based care provision, ${ }^{33-35}$ defensive medicine-driven by the threat of medical malpractice-may be another significant driver of cost and systematic reduction of value.
Interestingly, we observed that the associations observed between malpractice claim density and outcomes demonstrated a statistical interaction with patient income. First, we observed that the directionality of the association between discharge disposition and medical malpractice claim density differed depending on income. For lowerincome patients, higher malpractice claim density was associated with nonhome discharge. Conversely, for higherincome patients, higher malpractice claim density was associated with home discharge. This may reflect concerns about home support and resources for lower-income patients. Second, when conducting stratified analyses, higher malpractice claim density was associated with decreased LOS, opposite in direction to the nonstratified analysis in which higher malpractice claim density was associated with increased LOS. This finding suggests that the interaction between malpractice claim density and income is negative, and the magnitude of the effect of income on LOS is greater than the main effect of malpractice claim density on LOS. Last-in contrast to the overall analysisfor those from the lowest income quartiles, spinal fusions in patients from states with higher malpractice claim frequency were associated with decreased mortality. This may reflect the "cherry-picking" of healthier patients and lower-risk procedures in low-income patients. This may be an additional impediment to surgical care that may be pursued further in future investigations.

Neurosurgeons may be particularly sensitive to the medical malpractice environment, because they are the most likely physicians to be sued. ${ }^{10}$ In a survey of neurosurgeons, a majority (64\%) reported that malpractice claims were a major burden, with many substantially altering their practice due to liability concerns, such as by eliminating high-risk procedures. ${ }^{30} \mathrm{In}$ another survey not specific to neurosurgeons, $42 \%$ of respondents reported that they had restricted their practice due to litigation concerns, including eliminating high-risk procedures and avoiding medically complex patients or patients perceived to be litigious. ${ }^{31}$ Within neurosurgery, spine surgery faces the highest risk of litigation. ${ }^{13-15}$ This avoidance of highrisk but necessary procedures may result in a barrier or delay to important care, resulting paradoxically in harm to patients. Our data suggest that this may be a particular concern in lower-income patients. Tort reform, of great interest to multiple stakeholders, including patients, surgeons, payers, hospitals, and policymakers, may have the potential to mitigate these access barriers, decrease costs, and improve care. Tort reform laws have already been linked to decreases in excess imaging use. ${ }^{36}$ Another series of studies examining the relatively recent tort reform in Texas found that reform increased the number of physicians per capita in 20 of 22 trauma service areas. ${ }^{4}$ They also found that the reform lowered annual lawsuits by more than $50 \% .{ }^{37}$ However, this was also accompanied by increases in medical board complaints, disciplinary action, and license revocations, ${ }^{38}$ underscoring other mechanisms for corrective justice. In the states we found to have the lowest frequency of malpractice claims, a number of different tort reform measures have been enacted, such as damage caps (Hawaii, Massachusetts, Maine, Maryland, New Jersey, Alaska); joint liability reform (Hawaii, Con- 
necticut, New Hampshire, New Jersey, Alaska, Arizona); collateral source reform (Rhode Island, Connecticut, Massachusetts, Maine, New Jersey, Alaska, Arizona); and limiting attorney fees (Hawaii, Connecticut, Massachusetts, New Hampshire, Maine, New Jersey, Alaska). ${ }^{39}$

The significant associations between medical malpractice claim density and outcomes following spinal fusion surgery suggests that modeling of death, discharge disposition, LOS, and hospital charges would not be optimal without inclusion of claim density as a variable-something that has been unmodeled previously. Using robust machine learning techniques, we found it possible to predict death and discharge disposition with areas under the curve of 0.94 and 0.87 , respectively, following spinal fusion surgery by using data contained within the NIS, NPDB, and Area Resource File. Similarly, models predicting LOS and total charges performed with $\mathrm{R}^{2}$ values of 0.55 and 0.60 , respectively. These high-performing models may be leveraged by multiple stakeholders ${ }^{40}$ including patients, surgeons, hospital administrators, case managers planning discharge, and payers. For patients and surgeons the models may aid in the surgical decision-making process and perioperative planning. For hospital administrators and case managers planning discharge, these models may aid in efficient resource allocation. ${ }^{41}$ For payers, these models may inform reimbursement patterns. ${ }^{42}$ Machine learning modeling has been increasingly applied to spinal outcomes. ${ }^{40,43,44}$ With the addition of new features-such as medicolegal climate-machine learning approaches will only improve in their predictive capacity. Although our statistical analyses provide evidence demonstrating an association between malpractice claims and discharge-level parameters (death, LOS, discharge disposition, and charges), our machine learning analyses suggest that we can predict these parameters with reasonable accuracy by using algorithms trained with a large data set. Therefore, leveraging machine learning with a large data set provides powerful predictive tools for treating patients optimally based on patient and environmental characteristics-including malpractice claim density-that are readily reported. Machine learning methods, such as the GBC and GBR used in our analysis, allow us to predict discharge-level parameters by modeling complex variables' interactions. This avoids relying on stringent and sometimes wrong assumptions such as those required of standard regression models. By using flexible methods, we achieve better predictions of these parameters.

\section{Limitations}

This investigation relies on data sourced from an administrative data set and thus holds the inherent limitations. Additionally, the study uses data from 2005 to 2010 (years in which discharges in the NIS were identifiable by state). State designation was required to link discharges to state malpractice claim frequency and practitioner density. Therefore, it is possible that a hypothetical analysis with more recent information may yield different findings. Ultimately, however, with the latest available nationally representative data set, our study shows that the frequency of malpractice claims by state is associated with disparate outcomes following spinal fusion procedures in the US. Additionally, the NPDB-despite consideration as the most comprehensive database on medical malpractice payments in the US ${ }^{16,29}$-is not without several limitations. The NPDB provides information on the frequency of malpractice claim payments on behalf of physicians in general. Therefore, information is not known about the frequency of claims that were not paid and claim payments on behalf of spine surgeons specifically.

\section{Conclusions}

Spinal fusion procedures from states with a higher frequency of medical malpractice claims were associated with increased odds of nonhome discharge, longer lengths of hospitalization, and higher total charges despite adjustment for various covariates. Patient income demonstrates a significant interaction with these associations, with lower-income patients yielding a correlation between higher frequency of malpractice claims, and lower mortality and claim density exerting opposing associations with discharge disposition depending on patient income. This suggests that the frequency of malpractice claims, serving as a proxy for medicolegal climate, may alter practice patterns for spine surgeons. This may have important implications for healthcare and tort reform. Machine learning models including medical malpractice claim density were satisfactory in prediction and may be leveraged for preoperative decision-making, resource allocation, and reimbursement.

\section{References}

1. Mello MM, Chandra A, Gawande AA, Studdert DM. National costs of the medical liability system. Health Aff (Millwood). 2010;29(9):1569-1577.

2. Mello MM, Studdert DM, DesRoches CM, et al. Caring for patients in a malpractice crisis: physician satisfaction and quality of care. Health Aff (Millwood). 2004;23(4):42-53.

3. Mello MM, Studdert DM, DesRoches CM, et al. Effects of a malpractice crisis on specialist supply and patient access to care. Ann Surg. 2005;242(5):621-628.

4. Stewart RM, West M, Schirmer R, Sirinek KR. Tort reform is associated with significant increases in Texas physicians relative to the Texas population. J Gastrointest Surg. 2013;17(1): 168-178.

5. Lepard JR, Walters BC, Rozzelle CJ. Damage capitation in the modern liability climate: a primer for neurosurgeons and systematic review of the literature. J Neurosurg Spine. 2018; 28(4):446-454.

6. Konety BR, Dhawan V, Allareddy V, Joslyn SA. Impact of malpractice caps on use and outcomes of radical cystectomy for bladder cancer: data from the surveillance, epidemiology, and end results program. J Urol. 2005;173(6):2085-2089.

7. Bilimoria KY, Sohn MW, Chung JW, et al. Association between state medical malpractice environment and surgical quality and cost in the United States. Ann Surg. 2016;263(6): 1126-1132.

8. Minami CA, Sheils CR, Pavey E, et al. Association between state medical malpractice environment and postoperative outcomes in the United States. J Am Coll Surg. 2017;224(3): 310-318.e2.

9. Mello MM, Frakes MD, Blumenkranz E, Studdert DM. Malpractice liability and health care quality: a review. JAMA. 2020;323(4):352-366.

10. Jena AB, Seabury S, Lakdawalla D, Chandra A. Malpractice risk according to physician specialty. $N$ Engl J Med. 2011; 365(7):629-636. 
11. Thomas R, Gupta R, Griessenauer CJ, et al. Medical malpractice in neurosurgery: a comprehensive analysis. World Neurosurg. 2018;110:e552-e559.

12. Bekelis K, Missios S, Wong K, MacKenzie TA. The practice of cranial neurosurgery and the malpractice liability environment in the United States. PLoS One. 2015;10(3):e0121191.

13. Daniels AH, Ruttiman R, Eltorai AEM, et al. Malpractice litigation following spine surgery. J Neurosurg Spine. 2017; 27(4):470-475.

14. Elsamadicy AA, Sergesketter AR, Frakes MD, Lad SP. Review of neurosurgery medical professional liability claims in the United States. Neurosurgery. 2018;83(5):997-1006.

15. Rovit RL, Simon AS, Drew J, et al. Neurosurgical experience with malpractice litigation: an analysis of closed claims against neurosurgeons in New York State, 1999 through 2003. J Neurosurg. 2007;106(6):1108-1114.

16. Missios S, Bekelis K. Spine surgery and malpractice liability in the United States. Spine J. 2015;15(7):1602-1608.

17. HCUP. NIS Description of Data Elements. Agency for Healthcare Research and Quality. Accessed September 11, 2020. https://www.hcup-us.ahrq.gov/db/nation/nis/nisdde.jsp

18. Charlson ME, Pompei P, Ales KL, MacKenzie CR. A new method of classifying prognostic comorbidity in longitudinal studies: development and validation. J Chronic Dis. 1987; 40(5):373-383.

19. Buuren SV, Groothuis-Oudshoorn K. MICE: Multivariate imputation by chained equations in R. J Stat Softw. 2011; 45(3):1-67.

20. Robins JM, Rotnitzky A. Semiparametric efficiency in multivariate regression models with missing data. J Am Stat Assoc. 1995;90(429):122-129.

21. Funk MJ, Westreich D, Wiesen C, et al. Doubly robust estimation of causal effects. Am J Epidemiol. 2011;173(7): 761-767.

22. Cole SR, Hernán MA. Constructing inverse probability weights for marginal structural models. Am J Epidemiol. 2008;168(6):656-664.

23. Freedman DA. On the so-called "Huber Sandwich Estimator" and "Robust Standard Errors." Am Stat. 2006;60(4):299-302.

24. Bell ML, Fairclough DL. Practical and statistical issues in missing data for longitudinal patient-reported outcomes. Stat Methods Med Res. 2014;23(5):440-459.

25. Molenberghs G, Kenward MG. Missing Data in Clinical Studies. John Wiley \& Sons; 2007.

26. Schafer JL. Analysis of Incomplete Multivariate Data. CRC Press; 1997.

27. Ayilara OF, Zhang L, Sajobi TT, et al. Impact of missing data on bias and precision when estimating change in patientreported outcomes from a clinical registry. Health Qual Life Outcomes. 2019;17(1):106.

28. Minami CA, Chung JW, Holl JL, Bilimoria KY. Impact of medical malpractice environment on surgical quality and outcomes. J Am Coll Surg. 2014;218(2):271-278.e1-9.

29. Baicker K, Fisher ES, Chandra A. Malpractice liability costs and the practice of medicine in the Medicare program. Health Aff (Millwood). 2007;26(3):841-852.

30. Nahed BV, Babu MA, Smith TR, Heary RF. Malpractice liability and defensive medicine: a national survey of neurosurgeons. PLoS One. 2012;7(6):e39237.

31. Studdert DM, Mello MM, Sage WM, et al. Defensive medicine among high-risk specialist physicians in a volatile malpractice environment. JAMA. 2005;293(21):2609-2617.

32. Sethi MK, Obremskey WT, Natividad H, et al. Incidence and costs of defensive medicine among orthopedic surgeons in the United States: a national survey study. Am J Orthop. 2012;41(2):69-73.

33. Burwell SM. Setting value-based payment goals-HHS efforts to improve U.S. health care. N Engl J Med. 2015; 372(10):897-899.
34. Gentry S, Badrinath P. Defining health in the era of valuebased care: lessons from England of relevance to other health systems. Cureus. 2017;9(3):e1079.

35. Rosenbaum S. The Patient Protection and Affordable Care Act: implications for public health policy and practice. Public Health Rep. 2011;126(1):130-135.

36. Li S, Dor A, Deyo D, Hughes DR. The impact of state tort reforms on imaging utilization. J Am Coll Radiol. 2017;14(2): 149-156.

37. Sage WM, Harding MC, Thomas EJ. Resolving malpractice claims after tort reform: experience in a self-insured Texas public academic health system. Health Serv Res. 2016;51(suppl 3):2615-2633.

38. Stewart RM, Love JD, Rocheleau LA, Sirinek KR. Tort reform is associated with more medical board complaints and disciplinary actions. J Am Coll Surg. 2012;214(4):567-573.

39. American Medical Association. State Laws Chart II: Liability Reforms. Accessed September 11, 2020. https://www. ama-assn.org/media/10161/download

40. Ames CP, Smith JS, Pellisé F, et al. Development of predictive models for all individual questions of SRS-22R after adult spinal deformity surgery: a step toward individualized medicine. Eur Spine J. 2019;28(9):1998-2011.

41. Lubelski D, Ehresman J, Feghali J, et al. Prediction calculator for nonroutine discharge and length of stay after spine surgery. Spine J. 2020;20(7):1154-1158.

42. Kuo CY, Yu LC, Chen HC, Chan CL. Comparison of models for the prediction of medical costs of spinal fusion in Taiwan diagnosis-related groups by machine learning algorithms. Healthc Inform Res. 2018;24(1):29-37.

43. Scheer JK, Osorio JA, Smith JS, et al. Development of validated computer-based preoperative predictive model for proximal junction failure (PJF) or clinically significant PJK with $86 \%$ accuracy based on 510 ASD patients with 2-year follow-up. Spine (Phila Pa 1976). 2016;41(22):E1328-E1335.

44. Scheer JK, Osorio JA, Smith JS, et al. Development of a preoperative predictive model for reaching the Oswestry Disability Index minimal clinically important difference for adult spinal deformity patients. Spine Deform. 2018;6(5): 593-599.

\section{Disclosures}

Dr. Chan receives research support for an unrelated study from Orthofix Medical. Dr. Dhall is a consultant for and has received honoraria from DePuy Spine and Globus Medical. Dr. Chou is a consultant for and receives royalties from Globus. Dr. Mummaneni is a consultant for DePuy Synthes, Globus, and Stryker; has direct stock ownership in Spinicity/ISD; receives non-studyrelated clinical/research support from NREF and ISSG; receives royalties from DePuy Synthes, Thieme Publishing, and Springer Publishing; and has a grant from AO Spine.

\section{Author Contributions}

Conception and design: DiGiorgio, Chan, Pennicooke. Acquisition of data: DiGiorgio, Chan, Shahrestani, Ballatori. Analysis and interpretation of data: DiGiorgio, Chan, Santacatterina, Pennicooke, Shahrestani, Ballatori. Drafting the article: DiGiorgio, Chan, Santacatterina, Pennicooke, Shahrestani, Ballatori, Burke, Manley, Tarapore, Huang, Dhall, Chou, Mummaneni. Critically revising the article: all authors. Reviewed submitted version of manuscript: all authors. Statistical analysis: Santacatterina. Administrative/technical/material support: DiGiorgio. Study supervision: DiGiorgio.

\section{Correspondence}

Anthony M. DiGiorgio: University of California, San Francisco, CA. anthony.digiorgio@ucsf.edu. 